\title{
Hip fractures in the elderly: operative versus nonoperative management
}

Eileen Tay, MRCS, FRCS

INTRODUCTION Hip fractures are common in the elderly. Published studies have not shown significant differences in mortality rates between hip fracture patients who were managed nonoperatively and operatively. This retrospective study looked at 340 patients with hip fractures who were admitted to a local hospital over one year, and compared the long-term mortality between those treated operatively and nonoperatively.

METHODS All patients with hip fractures were identified retrospectively from the hospital's hip registry. Mortality data was collected through nationwide electronic medical records and telephone interviews.

RESULTS Overall mortality rates at one (14.4\%) and two years (24.4\%) were comparable to those of other studies. Hip fracture patients who were treated nonoperatively had a higher risk of mortality at both one (29.8\%) and two years $(45.6 \%)$ after fracture $(p<0.05)$. Their risk of mortality was four times higher at one year and three times higher at two years after fracture than the operative group. Patients with a higher American Society of Anesthesiologists (ASA) grade did not show an increased risk in mortality compared to patients with a lower ASA grade at both one year $(p=0.072)$ and two years $(p=0.360)$ after fracture.

CONCLUSION Elderly patients with hip fractures should be managed surgically and counselled regarding the increased risk of mortality if treated nonoperatively.

Keywords: hip fracture, mortality, nonoperative management

\section{INTRODUCTION}

Hip fractures in the elderly are a common problem worldwide, and its incidence is expected to increase due to the ageing population. ${ }^{(1-3)}$ Most patients with hip fractures, once deemed medically fit, are treated surgically as soon as possible. ${ }^{(4)}$ However, with the ageing population, ${ }^{(5)}$ the proportion of hip fracture patients with multiple medical comorbidities is increasing, affecting the management of these patients. The outcomes of hip fracture patients who were managed nonoperatively are useful for the physician's decision-making process. This retrospective study looks at the difference in long-term mortality between patients who were managed operatively and nonoperatively.

\section{METHODS}

All patients with hip fractures admitted to the Department of Orthopaedics, Tan Tock Seng Hospital, Singapore, from 1 January 2008 to 31 December 2008 were identified retrospectively from the hospital's hip registry. Patients were selected for the study based on the following inclusion criteria: low-energy intracapsular and extracapsular hip fractures, non-pathological fracture, and patient age $\geq 60$ years.

During hospital admission, information such as demographic characteristics, patient comorbidities, ambulatory status on admission and discharge, American Society of Anesthesiologists (ASA) score, presence of postoperative complications, length of stay, and discharge location were recorded. The ASA classification scale assesses the patients' preoperative physical state. All hip fracture patients were started on a hip fracture clinical pathway and co-managed by a multidisciplinary team of orthopaedic surgeons, geriatricians, physiotherapists, occupational therapists, medical social workers and case managers. All patients received a general preoperative workup on admission. Referrals were also made to the appropriate specialties (e.g. cardiology, respiratory medicine) for further investigation of particular comorbidities, if necessary.

Surgery was offered to all patients who were medically fit and performed on those who gave their consent. The type of surgery performed depended on the type of fracture and the patient's premorbid functional status. Procedures performed included screw fixation, extramedullary sliding device fixation, intramedullary nailing and hemiarthroplasty. Surgery was performed as early as possible and early mobilisation was initiated after the operation. Patients were offered nonoperative management if, despite medical optimisation, the risk of death in the perioperative period outweighed the benefits of surgical intervention. Patients who were managed nonoperatively were mobilised early with bedto-chair transfers to prevent problems of prolonged recumbency. Mechanical prophylaxis for deep venous thrombosis, in the form of graduated compression stockings or intermittent pneumatic calf compression devices, was initiated for all patients with hip fractures immediately upon admission to the ward.

Each patient was followed up for at least two years. Information regarding mortality was obtained through electronic hospital records and telephone interviews 24-30 months after admission. Telephone interviews were conducted with the patients, attending nursing staff or main carers after verbal consent was obtained. The main outcome measures were one- and two-year mortality rates. Risk of death between patients managed 
nonoperatively and operatively was compared using relative risk calculations with 95\% confidence intervals.

Statistical analysis was done using Stata 13 (StataCorp LP, College Station, TX, USA). Independent two-sample $t$-test was used to analyse the data. A p-value $<0.05$ indicated statistical significance.

\section{RESULTS}

A total of 390 patients were identified using the hospital's hip registry. Three patients were excluded as they were $<60$ years of age and 47 patients were lost to follow-up; attempts were made to contact them via the telephone numbers recorded in the hospital patient database. Table I shows the profiles of the remaining 340 patients. The patients' total mean age was 80 (range 60-100) years. The mean age was 78 years and 81 years among the men and women, respectively. The mean age was similar for both the operative (78.8 years) and nonoperative groups (82.8 years). The majority of the study population were female ( $81.2 \%)$. There was a higher female predilection in the operative group compared to the nonoperative group (female-to-male ratio of $6: 1$ vs. 5:2, respectively). Both groups had similar proportions of patients in each ASA grade. Most of the patients were ASA Grade III (52.2\% in operative group, $60.5 \%$ in nonoperative group).

$226(66.5 \%)$ patients underwent surgical treatment. Patients with extracapsular hip fractures were treated with a sliding hip screw or intramedullary device. Undisplaced intracapsular hip fractures were fixed with cancellous screws and patients with displaced intracapsular hip fractures underwent hemiarthroplasty. Operative delay was 0-21 days, with a mean time of five days.

Mean length of hospital stay for all the patients was 14.3 (range 1-83) days. Duration of hospitalisation was similar for patients who underwent surgery and those who were treated conservatively ( 14.3 days vs. 14.1 days, respectively). A majority of the patients who underwent the operation were discharged to a step-down facility $(62.4 \%)$, whereas most of the patients treated nonoperatively were able to return home on discharge (50.9\%). 22 patients developed complications (e.g. cardiac or cerebrovascular events, pneumonia, thromboembolic disease, urinary tract infections, wound complications) during their stay (Table II). 16 of these patients had undergone surgery. Overall, pneumonia and urinary tract infections were the most common complications $(2.6 \%$ and $2.4 \%$, respectively), followed by pulmonary embolism (1.2\%). Two patients had acute wound infection postoperatively, one of which was superficial. The other patient had a deep wound infection that was treated with long-term intravenous antibiotics; no removal or revision of the implant was necessary.

A total of 49 and 83 patients died at the one-year and two-year follow-up, respectively. 4 (3.5\%) patients who were managed nonoperatively died during hospital admission; one died from a urinary tract infection and the other three due to pneumonia. The overall mortality rate was $14.4 \%$ at one year and $24.4 \%$ at two years (Table III); there was a rising trend with advanced age. Compared to women, men had higher mortality rates at both one year $(25.0 \%$ vs. $12.0 \%$, respectively) and two
Table I. Demographics of patients treated operatively and nonoperatively.

\begin{tabular}{lccr}
\hline Characteristic & \multicolumn{2}{c}{ No. (\%) } & p-value \\
\cline { 2 - 3 } & $\begin{array}{c}\text { Operative } \\
\text { (n= 226) }\end{array}$ & $\begin{array}{c}\text { Nonoperative } \\
\text { ( } \mathbf{n}=\mathbf{1 1 4})\end{array}$ & \\
\hline Age* (yr) & $78.8 \pm 8.20$ & $82.8 \pm 8.26$ & $<0.05$ \\
Gender & & & 0.83 \\
Male & $32(14.2)$ & $32(28.1)$ & \\
Female & $194(85.8)$ & $82(71.9)$ & \\
ASA grade & & & 0.31 \\
I & $2(0.9)$ & $3(2.6)$ & \\
II & $105(46.5)$ & $42(36.8)$ & \\
III & $118(52.2)$ & $69(60.5)$ & \\
IV & $1(0.4)$ & 0 & 0.81 \\
Mean length of stay (day) & 14.3 & 14.1 & 0.64 \\
Discharge location & & & \\
Home & $72(31.9)$ & $58(50.9)$ & \\
Nursing home & $13(5.8)$ & $25(21.9)$ & \\
Rehab/community & $141(62.4)$ & $27(23.7)$ & \\
step-down facility & & & \\
Died & 0 & $4(3.5)$ & \\
\hline
\end{tabular}

* Data presented as mean \pm standard deviation. ASA: American Society of Anesthesiologists

Table II. Complication rates of patients treated operatively and nonoperatively.

\begin{tabular}{llcr}
\hline Parameter & \multicolumn{3}{c}{ No. (\%) } \\
\cline { 2 - 4 } & $\begin{array}{c}\text { Operative } \\
(\mathbf{n}=\mathbf{2 2 6})\end{array}$ & $\begin{array}{c}\text { Nonoperative } \\
\mathbf{( n = 1 1 4 )}\end{array}$ & $\begin{array}{c}\text { Total } \\
(\mathbf{n}=\mathbf{3 4 0})\end{array}$ \\
\hline Incidence & $16(7.1)$ & $6(5.3)$ & $22(6.5)$ \\
Complication* $^{*}$ & & & \\
Acute myocardial infarction & $2(0.9)$ & 0 & $2(0.6)$ \\
Cerebrovascular ischaemia & $1(0.4)$ & $2(1.8)$ & $3(0.9)$ \\
Pneumonia & $6(2.7)$ & $3(2.6)$ & $9(2.6)$ \\
Urinary tract infection & $6(2.7)$ & $2(1.8)$ & $8(2.4)$ \\
Deep venous thrombosis & $2(0.9)$ & 0 & $2(0.6)$ \\
Pulmonary embolism & $3(1.3)$ & $1(0.9)$ & $4(1.2)$ \\
Wound infection & $2(0.9)$ & 0 & $2(0.6)$ \\
\hline
\end{tabular}

*Some patients developed more than one complication.

Table III. Overall mortality rates of patients $(n=340)$.

\begin{tabular}{lcccc}
\hline Parameter & No. (\%) & p-value & No. (\%) & p-value \\
\cline { 2 - 2 } & 1 yr & & $\mathbf{2 ~ y r}$ & \\
\hline Treatment & & $<0.05$ & & $<0.05$ \\
$\quad$ Operative & $15(4.4)$ & & $31(9.1)$ & \\
$\quad$ Nonoperative & $34(10.0)$ & & $52(15.3)$ & \\
Age (yr) & & $<0.05$ & & $<0.05$ \\
$60-69$ & 0 & & $3(0.9)$ & \\
$70-79$ & $12(3.5)$ & & $20(5.9)$ & \\
$80-89$ & $23(6.8)$ & & $37(10.9)$ & \\
$\geq 90$ & $14(4.1)$ & & $23(6.8)$ & \\
Gender & & 0.39 & & \\
Male $(n=64)$ & $16(25.0)$ & & $30(46.9)$ & \\
Female $(n=276)$ & $33(12.0)$ & & $53(19.2)$ & \\
\hline
\end{tabular}


Table IV. Mortality rates by American Society of Anesthesiologists (ASA) grading.

\begin{tabular}{|c|c|c|c|c|}
\hline \multirow[t]{2}{*}{ Parameter } & \multicolumn{3}{|c|}{ No. (\%) } & \multirow[t]{2}{*}{ p-value } \\
\hline & $\begin{array}{l}\text { Operative } \\
(n=226)\end{array}$ & $\begin{array}{c}\text { Nonoperative } \\
\quad(n=114)\end{array}$ & $\begin{array}{c}\text { Total } \\
(n=340)\end{array}$ & \\
\hline $1 \mathrm{yr}$ & & & & 0.072 \\
\hline ASA I & 0 & $1(0.9)$ & $1(0.3)$ & \\
\hline ASA II & $4(1.8)$ & $10(8.8)$ & $14(4.1)$ & \\
\hline ASA III & $11(4.9)$ & $23(20.2)$ & $34(10.0)$ & \\
\hline ASA IV & 0 & 0 & 0 & \\
\hline $2 \mathrm{yr}$ & & & & 0.360 \\
\hline ASA I & $1(0.4)$ & $3(2.6)$ & $4(1.2)$ & \\
\hline ASA II & $11(4.9)$ & $15(13.2)$ & $26(7.6)$ & \\
\hline ASA III & $19(8.4)$ & $34(29.8)$ & $53(15.6)$ & \\
\hline ASA IV & 0 & 0 & 0 & \\
\hline
\end{tabular}

Table V. Mortality rates for operative vs. nonoperative treatment.

\begin{tabular}{lccc}
\hline Parameter & \multicolumn{2}{c}{ No. (\%) } & $\begin{array}{c}\text { Relative risk } \\
\text { (95\% CI) }\end{array}$ \\
\cline { 2 - 3 } & $\begin{array}{c}\text { Operative } \\
\text { (n = 226) }\end{array}$ & $\begin{array}{c}\text { Nonoperative } \\
\text { (n = 114) }\end{array}$ & \\
\hline Overall & & & \\
1 yr & $15(6.6)$ & $34(29.8)$ & $4.49(2.56-7.90)$ \\
2 yr & $31(13.7)$ & $52(45.6)$ & $3.33(2.26-4.88)$ \\
ASA II & $4(1.8)$ & $10(8.8)$ & $6.25(2.05-18.80)$ \\
1 yr & $11(4.9)$ & $15(13.2)$ & $3.41(1.71-6.80)$ \\
2 yr & & & \\
ASA III & $11(4.9)$ & $23(20.2)$ & $3.58(1.86-6.88)$ \\
1 yr & $19(8.4)$ & $34(29.8)$ & $3.06(1.90-4.93)$ \\
2 yr & & & \\
\hline
\end{tabular}

Confidence interval $(\mathrm{Cl})$ presented as range. ASA: American Society of Anesthesiologists

years (46.9\% vs. $19.2 \%$, respectively) after a hip fracture. There was also a higher rate of mortality in patients classified as ASA Grade III compared with ASA Grade II, one year after fracture (Table IV).

At one year after fracture, the mortality risk of patients who were managed nonoperatively was at least four times higher than that of those who underwent operative treatment. At two years after fracture, however, the risk was three times higher in patients who did not undergo surgical treatment. When the mortality rates were stratified by ASA grade, the risk of mortality was still higher in patients who had nonoperative management. However, patients with a higher ASA grade did not show an increased risk in mortality compared to patients with a lower ASA grade (Table V).

\section{DISCUSSION}

Hip fractures have conventionally been managed operatively, as surgical treatment enables earlier mobilisation and results in better functional outcomes, ${ }^{(6)}$ improved quality of life, ${ }^{(7)}$ shorter length of stay and decreased hospitalisation costs. ${ }^{(8)}$

In our study, there was a significantly higher mortality rate among patients who were treated nonoperatively at both one and two years after a hip fracture. This difference remained significant even after stratification by ASA grading. A review by the Cochrane Collaboration ${ }^{(9)}$ found no differences in long-term mortality rates. In a retrospective study, Jain et $\mathrm{al}^{(10)}$ evaluated 62 patients with hip fractures who were managed conservatively, of whom 41 were treated with traction or bed rest, and the remaining 21 were mobilised early. Overall 30-day mortality in the operatively treated group was higher compared to those who were treated nonoperatively. Hossain et $\mathrm{al}^{(11)}$ prospectively identified 25 patients with hip fractures who were managed nonoperatively and compared them to a matched group of patients who underwent surgery. At one year, there was no statistically significant difference in mortality rates between both groups. Gregory et al ${ }^{(12)}$ reported similar mortality rates at one year in patients who were treated operatively and nonoperatively. However, in all these studies, the number of patients who were treated nonoperatively was small, which may have accounted for the non-significant differences in the mortality rates. The only study with a large number of patients who were managed conservatively was by Chariyalertsak et al, (13) in which 330 patients in Chiang Mai, Thailand, were followed up on and $57 \%$ of the patients with hip fractures were managed conservatively. Their study found that patients who were managed nonoperatively had almost double the mortality risk than those who were treated surgically. Nonoperative management was also a significant prognostic factor for death.

The percentage of patients who were treated nonoperatively in this study is higher than that reported worldwide. This may be due to the perception in the local population that the elderly are generally unable to tolerate the stress of major surgery, and the reluctance of the patients themselves to undergo surgery due to fear. Our data showed that about half of the patients who were managed nonoperatively were discharged to home, although all of them were unable to ambulate even with assistance and needed help with transfers. This is likely due to good family support in Singapore for elderly patients; the majority live with their children, who often hire domestic help solely for the care of the patient. Therefore, patients have less impetus to regain their mobility and independence.

The one- and two-year mortality rates $(14.4 \%$ and $24.4 \%$, respectively) in our study are comparable to those of published studies on hip fractures in both Asian ${ }^{(14-18)}$ and Western populations. ${ }^{(19-25)}$ Although ASA grading has been found to negatively affect mortality rates, ${ }^{(20,26-28)}$ we found that this was not the case in our study. The one- and two-year mortality rates were not increased even after stratification by ASA grading.

The major limitation of this study is its retrospective nature. A significant number of patients were also lost to follow-up. The study could have been improved if comparisons were made between two matched cohorts. However, it must also be noted that the proportions of patients in each ASA grade were similar in the two groups.

In conclusion, hip fracture patients who were treated nonoperatively have a higher risk of mortality at both one and two years after fracture. Elderly patients with hip fractures should be managed surgically and counselled regarding the increased risk of mortality if they are treated nonoperatively. 


\section{REFERENCES}

1. Gullberg B, Johnell O, Kanis JA. World-wide projections for hip fracture. Osteoporos Int 1997; 7:407-13.

2. Koh LK, Saw SM, Lee J, et al; National Working Committee on Osteoporosis. Hip fracture incidence rates in Singapore 1991-1998. Osteoporos Int 2001; 12:311-8.

3. Haleem S, Lutchman L, Mayahi R, Grice JE, Parker MJ. Mortality following hip fracture: trends and geographical variations over the last 40 years. Injury 2008 Oct; 39:1157-63.

4. Parker MJ. Current concepts in the treatment of hip fracture. Z Gerontol Geriatr 2001; 34:74-7.

5. Cooper C, Campion G, Melton LJ 3rd. Hip fractures in the elderly: a worldwide projection. Osteoporos Int 1992; 2:285-9.

6. Kitamura S, Hasegawa Y, Suzuki S, et al. Functional outcome after hip fracture in Japan. Clin Orthop Relat Res 1998; (348):29-36.

7. Parker MJ, Myles JW, Anand JK, Drewett R. Cost-benefit analysis of hip fracture treatment. J Bone Joint Surg Br 1992; 74:261-4.

8. Lee $\mathrm{YH}$, Lim YW, Lam KS. Economic cost of osteoporotic hip fractures in Singapore. Singapore Med J 2008; 49:980-4.

9. Handoll HH, Parker MJ. Conservative versus operative treatment for hip fractures in adults. Cochrane Database Syst Rev 2008; (3):CD000337.

10. Jain R, Basinski A, Kreder HJ. Nonoperative treatment of hip fractures. Int Orthop 2003; 27:11-7.

11. Hossain M, Neelapala V, Andrew JG. Results of non-operative treatment following hip fracture compared to surgical intervention. Injury 2009; 40:418-21.

12. Gregory JJ, Kostakopoulou K, Cool WP, Ford DJ. One-year outcome for elderly patients with displaced intracapsular fractures of the femoral neck managed non-operatively. Injury 2010; 41:1273-6.

13. Chariyalertsak S, Suriyawongpisal P, Thakkinstain A. Mortality after hip fractures in Thailand. Int Orthop 2001; 25:294-7.

14. Ooi LH, Wong TH, Toh CL, Wong HP. Hip fractures in nonagenarians--a study on operative and non-operative management. Injury 2005; 36:142-7.

15. Tay YWA, Hong CC, Murphy D. Functional outcome and mortality in nonagenarians following hip fracture surgery. Arch Orthop Trauma Surg 2014; 134:765-72.
16. Lee AY, Chua BSY, Howe TS. One-year outcome of hip fracture patients admitted to a Singapore hospital: quality of life post-treatment. Singapore Med J 2007; 48:996-9.

17. Tsuboi M, Hasegawa Y, Suzuki S, Wingstrand H, Thorngren KG. Mortality and mobility after hip fracture in Japan: a ten-year follow-up. J Bone Joint Surg Br 2007; 89:461-6.

18. Nather A, Seow CS, lau P, Chan A. Morbidity and mortality for elderly patients with fractured neck of femur treated by hemiarthroplasty. Injury 1995; 26:187-90.

19. Neuman MD, Silber JH, Magaziner JS, et al. Survival and functional outcomes after hip fracture among nursing home residents. JAMA Intern Med 2014; 174:1273-80.

20. S ouml derqvist A, Ekstr ouml m W, Ponzer S, et al. Prediction of mortality in elderly patients with hip fractures: a two-year prospective study of 1,944 patients. Gerontology 2009; 55:496-504.

21. Kirke PN, Sutton M, Burke H, Daly L. Outcome of hip fracture in older Irish women: a 2-year follow-up of subjects in a case-control study. Injury 2002; 33:387-91.

22. Miller CW. Survival and ambulation following hip fracture. J Bone Joint Surg Am 1978; 60:930-4.

23. Lyons AR. Clinical outcomes and treatment of hip fractures. Am J Med 1997; 103:51S-63S

24. Baudoin C, Fardellone $\mathrm{P}$, Bean $\mathrm{K}$, et al. Clinical outcomes and mortality after hip fracture: a 2-year follow-up study. Bone 1996; 18(3 Suppl):149S$157 \mathrm{~S}$.

25. Kenzora JE, McCarthy RE, Lowell JD, Sledge CB. Hip fracture mortality. Relation to age, treatment, preoperative illness, time of surgery, and complications. Clin Orthop Relat Res 1984; (186):45-56.

26. Oztürk A1, Ozkan Y, Akgöz S, et al. The risk factors for mortality in elderly patients with hip fractures: postoperative one-year results. Singapore Med J 2010; 51:137-43.

27. Richmond J, Aharonoff GB, Zuckerman JD, Koval KJ. Mortality risk after hip fracture. J Orthop Trauma 2003; 17:53-6.

28. White BL, Fisher WD, Laurin CA. Rate of mortality for elderly patients after fracture of the hip in the 1980's. J Bone Joint Surg Am 1987; 69:1335-40 